\title{
FABRICATION OF PERIODIC ARRAYS OF MICROHOLES IN THIN Ag-FILMS BY FEMTOSECOND LASER PULSES
}

\author{
Nguyen Thi Huyen Trang ${ }^{1,2,3}$ \\ ${ }^{1}$ Ha Tinh University, Ha Tinh, 447, 26/3 street, Dai Nai ward, Ha Tinh city, Vietnam \\ ${ }^{2}$ Lebedev Physical Institute, Russian Academy of Sciences, Leninskii pr. 53, Moscow, \\ 119991 Russia \\ ${ }^{3}$ Moscow Institute of Physics and Technology (State University), Institutskii per. 9, \\ Dolgoprudnyi, Moscow region, 141700 Russia \\ *Email: trang.nguyenthihuyen@htu.edu.vn
}

Received: 16 March 2016; Accepted for publication: 25 November 2016

\begin{abstract}
Arrays of microholes with different diameters of $2,3,4 \mu \mathrm{m}$ and period $6 \mu \mathrm{m}$ were produced in thin silver films with thicknesses of $100,150 \mathrm{~nm}$ by using single femtosecond laser pulses with variable pulse energies, focused by different strong focusing optics. The fabricated microholes are regular in size and shape throughout large sample area. The irradiation using an ultrashort laser pulse results concern not only the melting of the film but also the exfoliation in the form of nanojets. Atomic force and electron microscopy studies have demonstrated the shape and dimension of the nanostructures. The threshold parameters of laser radiation for their formation are also determined by the thickness of a modified film ("size effect") and by the duration of a laser pulse owing to the lateral heat conduction in the films (nonlocal energy deposition effect). The mechanisms for microholes formation in the silver thin films by using the femtosecond laser pulses have been discussed.
\end{abstract}

Keywords: femtosecond laser, microholes, thin film, SEIRA.

\section{INTRODUCTION}

Nanoholes in thin metallic films are the most simple and popular nano-optical elements, providing in their apertures nanoscale transmission, frequency conversion and local enhancement of electromagnetic waves [1 - 3]. Currently, the basic nanohole characteristics (diameter, depth) are thoroughly studied in terms of focusing conditions, laser wavelength, energy and pulse width [4 - 7], demonstrating the minimal hole diameters - down to $30 \mathrm{~nm}$ - for nanosecond laser pulses $[8,9]$ in comparison with typical sub-micron holes produced by tightly focused ultrashort (femto- or sub-picosecond) laser pulses [2, 5, 10]. Ablation using short pulsed lasers (ns to fs) is one of the most common micro-fabrication techniques used for high precision 
drilling of micro-holes, cutting and patterning in metals and dielectrics [10 - 12]. It has been demonstrated that femtosecond pulses produce sharp borders with little or no thermal damage to the surround illumination volume due to the rapid energy deposition [2]. In contrast, nanosecond and even picosecond pulses produce thermal damage and reduce the quality of ablation [13]. At the same time, it was demonstrated that some of nanostructures formed on the surface of metal films (e.g., gold films) with femtosecond laser pulses can be reproduced with a cheaper and simpler nanosecond laser source. The arrays of nanoholes are an exciting new substrate for chemical sensing and enhanced spectroscopy $[4,7]$. This class of nanomaterials has the potential to provide a viable alternative to the commercial SPR-based sensors [13 - 15]. Further research could exploit this platform to develop nanostructures that support high field localization for single-molecule spectroscopy $[7,13]$.

Metal films with arrays of holes are now considered new plasmonic metamaterials. The history goes back to 1974 when Ulrich demonstrated and theoretically described a transmission resonance in the far-infrared region $\left(\sim 80 \mathrm{~cm}^{-1}\right)$ of electro-formed, freestanding $\mathrm{Cu}$ mesh with a square lattice of square holes (hole-to-hole spacing of $101 \mu \mathrm{m}$, hole width of $87 \mu \mathrm{m}$ and thickness of $5 \mu \mathrm{m}$ ) [16]. Glass et al. performed calculations in 1983 on sinusoidal biperiodic metal gratings regarding SP reflectivity resonances $(800 \mathrm{~nm}$ lattice, $514.5 \mathrm{~nm}$ wavelength of light, and Ag dielectric constants) [17]. In 1998 Ebbesen and co-workers fabricated square arrays of cylindrical holes in metallic films $(900 \mathrm{~nm}$ hole-to-hole spacing, $150 \mathrm{~nm}$ hole diameters, $200 \mathrm{~nm}$ thickness of silver) and measured unexpectedly large resonant transmissions in the visible and near IR regions [18].

In this work, applying above technology with femtosecond laser pulses, we demonstrate the possibility of the formation of nanojets and circular microholes on the surface of silver films with various thicknesses. The corresponding dynamic mechanisms are revealed by analyzing the topology of indicated nanostructures and thermo-physical conditions of their formation under the action of femtosecond laser radiation.

\section{MATERIALS AND METHODS}

In our experiments the samples of thin optical-quality silver (Ag) film with thicknesses $h \approx$ $100 \mathrm{~nm}, 150 \mathrm{~nm}$ were deposited onto a 1-mm thick $\mathrm{CaF}_{2}$ substrate by magnetron sputtering (SC7620 Quorum Technologies) of a commercial Ag plate (99.99 \%) in argon. The film was arranged on a three-dimensional motorized micro-stage under PC control. A fiber laser facility based on $\mathrm{Yb}^{+}$ions (Satsuma, Amplitude Systems) [16] was used as a source of ultrashort laser pulses. The microholes were produced via single-shot ablation of the film by moderate objective (NA $\approx 0.25$ ), laser wavelength of $515 \mathrm{~nm}$, pulse width of about $\tau_{\text {las }} \approx 220$-fs, and the maximum energy in a pulse up to $4 \mu \mathrm{J}$. The spatial distribution at the output of the single-mode fiber corresponded to the $\mathrm{TEM}_{00}$ mode. Laser radiation was focused on the surface of the sample in air formed a spot with the radius $\mathrm{R}_{1 / \mathrm{e}} \approx 1.5 \mu \mathrm{m}$, resulting in the corresponding variation of $d$ in the range $\approx 1-4 \mu \mathrm{m}$. The radius of the focusing spot at a level of $1 / \mathrm{e}$ was calculated in the absence of spherical and chromatic aberrations using the formula (1):

$$
w_{\text {opt }}=\frac{\lambda_{\text {las }} \sqrt{n_{0}^{2}-N A^{2}}}{\sqrt{2} \pi N A}
$$

for a Gaussian beam in air (refractive index $\mathrm{n}_{0} \approx 1$ ) and was $0.45 \mu \mathrm{m}$.

The scheme of fabrication microholes in thin metallic film using femtosecond laser pulses was demonstrated in the Figure 1 . The resulting sensors with diameter $d_{1} \approx 2 \mu \mathrm{m}, d_{2} \approx 3 \mu \mathrm{m}$ and 
$d_{3} \approx 4 \mu \mathrm{m}$ and period $6 \mu \mathrm{m}$ were visualized by means of a JEOL $7001 \mathrm{~F}$ scanning electron microscope with a magnification up to $500000 \times$, as well as an Al'tami-6 optical metallographic microscope with an instrumental magnification up to $2000 \times$.

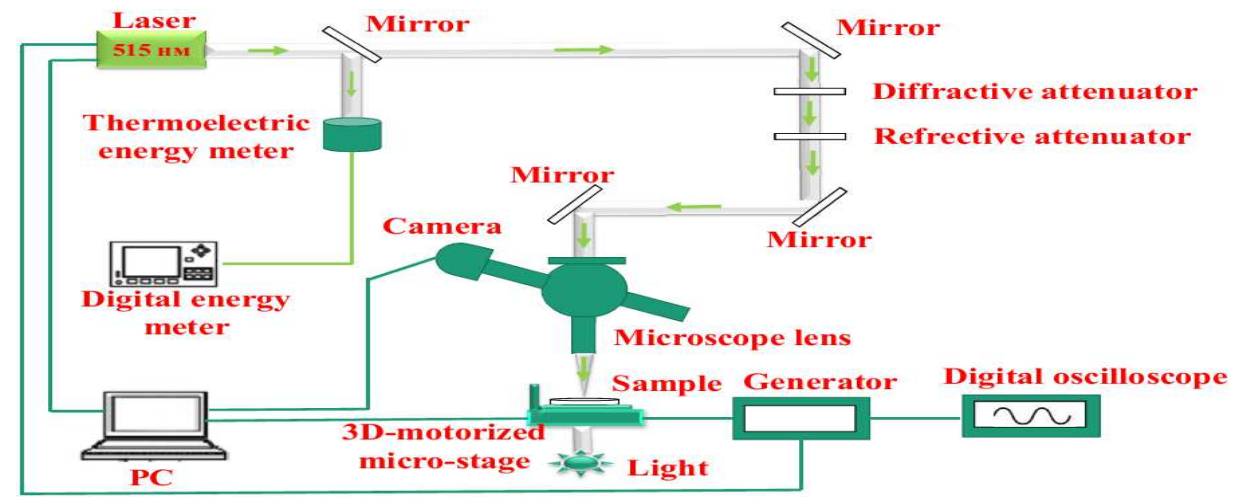

Figure 1. The schematic femtosecond laser pulses for fabrication microholes in thin metallic film.

\section{RESULTS AND DISCUSSION}

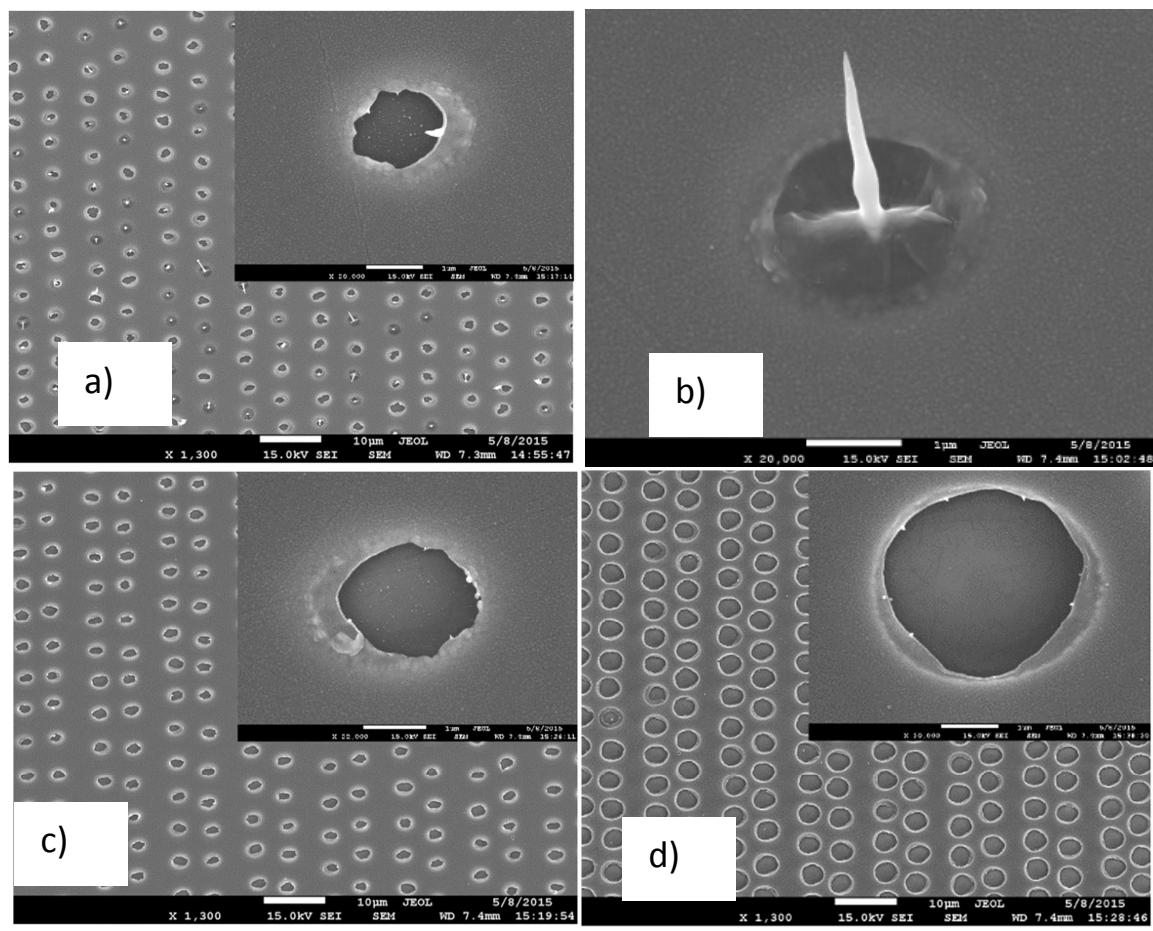

Figure 2. Scanning electron microscopy (SEM) image of the diffraction grating with diameter $\mathrm{d} \approx(\mathrm{a}, \mathrm{b}) 2$, (c) 3, (d) $4 \mu \mathrm{m}$ and period $\mathrm{p} \approx 6 \mu \mathrm{m}$ of microhole arrays in the $100 \mathrm{~nm}$ thick silver film formed by strongly focused ultrashort laser pulses with the energy $E \approx(\mathrm{a}, \mathrm{b}) 72$, (c) 80 , (c) $104 \mathrm{~nJ}$ in the single pulse ablation regime. (b) Magnified images of the microhole with diameter $\mathrm{d} \approx 2 \mu \mathrm{m}$ with the nanojet. Scale bar: $10 \mu \mathrm{m}$.

Diffraction grating with diameter $\mathrm{d} \approx 2 \mu \mathrm{m}$ and period $\mathrm{p} \approx 6 \mu \mathrm{m}$ of microhole arrays in the $100 \mathrm{~nm}$ thick silver film was fabricated (Figure 2a), when we used femtosecond laser pulses with 
energy $E \approx 72 \mathrm{~nJ}$. The irradiation by an ultrashort laser pulse results is not only the melting of the film but also in exfoliation in the form of a nanojet in the microhole (Figure 2b).

Figures $2 \mathrm{c}, 2 \mathrm{~d}$ show arrays of microholes with diameters $d_{2} \approx 3 \mu \mathrm{m}$ and $d_{3} \approx 4 \mu \mathrm{m}$ produced in the $100 \mathrm{~nm}$ thick silver film by a single ultrashort laser pulse with energy $E \approx 80,104 \mathrm{~nJ}$, respectively. The fabricated holes are regular in size and sharp throughout the sample area.

The presence of lateral heat transfer in the film at formation times of microholes within the heated region appears the characteristic radius $R_{t h, 1 / e}(\tau)=\sqrt{4 \chi \tau}$ ("thermal" microspot), where $\chi$ is high-temperature thermal diffusivity of the film and $\tau$ is the characteristic time scale of the formation of microholes. In view of the known high-temperature thermal diffusivity of silver is $\chi_{A g}(1000 \mathrm{~K}) \approx 1.6 \mathrm{~cm}^{2} / \mathrm{s}$, which is larger than that of the substrate $\chi(1000 \mathrm{~K}) \leq 0.1 \mathrm{~cm}^{2} / \mathrm{s}$. The dimensions of holes $\mathrm{R}_{\text {hole, } 1 / \mathrm{e}}(\mathrm{h})$ in the $h \approx 100 \mathrm{~nm}$ and $h \approx 150 \mathrm{~nm}$ thin silver films are much larger than the characteristic radius of holes at the thermal microspot of level 1/e $R_{t h, 1 / e}(1 \mathrm{~ns})=\sqrt{4 \chi_{A g} \tau} \sim 0.78 \mu \mathrm{m}$ (where $\left.\tau \sim h^{2} / \chi_{A g}(1000 \mathrm{~K}) \sim 1 \mathrm{~ns}\right)$. They were obtained by approximating the corresponding dependences $d_{\text {hole }}^{2}(\ln E)$ (Figure 4$)$, which are also much larger than "optical" radius $\mathrm{w}_{\text {opt }} \approx 0.45 \mu \mathrm{m}$.

The threshold fluence for the formation of microholes for the threshold energy $E_{\text {hole }}(h)$ is [9]:

$$
\Phi_{\text {hole }}(h)=\frac{E_{\text {hole }}}{\pi R_{\text {hole }, 1 / e}^{2}}\left(\frac{J}{c m^{2}}\right)
$$

Formula of energy density $\varepsilon$ for the formation of microholes is:

$$
\varepsilon=\frac{\Phi_{\text {hole }}(h)(1-R)}{h}\left(\frac{\mathrm{kJ}}{\mathrm{cm}^{3}}\right)
$$

where $R_{A g}=\left|\frac{n_{2}-n_{1}}{n_{2}+n_{1}}\right|^{2} \approx 0.82$ - the reflection coefficient of silver film in air, $\mathrm{n}_{1} \approx 1-$ the refractive index of air, $\mathrm{n}_{2}(\lambda=515 \mathrm{~nm}) \approx 0.05$ - the refractive index of thin silver film.

Table 1 shows the corresponding threshold fluences $\Phi_{\text {hole }}$, energy density $\varepsilon$ for the threshold energies with different thicknesses of Ag-film and radius of microholes.

Table 1. Parameters of microholes in thin Ag-film.

\begin{tabular}{|c|c|c|c|c|c|c|}
\hline Parameter & \multicolumn{3}{|c|}{$\mathrm{H}=100 \mathrm{~nm}$} & \multicolumn{3}{c|}{$\mathrm{h}=150 \mathrm{~nm}$} \\
\hline $\mathrm{R}_{\text {hole, } 1 / \mathrm{e}}, \mu \mathrm{m}$ & 1 & 1.5 & 2 & 1 & 1.5 & 2 \\
\hline $\mathrm{E}, \mathrm{nJ}$ & 72 & 80 & 104 & 160 & 176 & 220 \\
\hline$\Phi_{\text {hole }}(\mathrm{h}), \mathrm{J} / \mathrm{cm}^{2}$ & 2.29 & 1.13 & 1.08 & 5.09 & 2.49 & 1.75 \\
\hline$\varepsilon, \mathrm{kJ} / \mathrm{cm}^{3}$ & 41 & 20 & 19 & 61 & 30 & 21 \\
\hline$\Delta \mathrm{H}_{\text {vap }}, \mathrm{kJ} / \mathrm{cm}^{3}$ & \multicolumn{7}{|c|}{32} \\
\hline
\end{tabular}

The measured or calculated absorptances for thin metal films used in this work can be used to reliably estimate the total absorbed volume energy density $\varepsilon$ near the threshold fluences $\Phi$ to form the microholes. Furthermore, experimental proportionality between the threshold fluences for the formation of microholes and the thickness of the films used in this work allows us statistically estimate of $\varepsilon$. 
Similar estimates for $\varepsilon$ with the use of the threshold values $\Phi_{\text {hole }}(h)$ show that the total absorbed volume energy density approaches the enthalpy of vapor $\Delta \mathrm{H}_{\text {vap }}$ for the materials of the films. The evaporation in the case of uniformly heated thin films is possible not only from the outer surface, but also from the film-substrate interface. In the latter case, the pressure of formed vapor cavity increases monotonically and exfoliates (with removal) the film at a certain threshold pressure of vapor.

Fabrication of the microhole in the same diameter of $150 \mathrm{~nm}$ silver film was controlled by focusing femtosecond laser pulses with the energy higher than for $100 \mathrm{~nm}$ silver films. The microholes of Figure 3 have been fabricated on this substrate at laser energy of $E \approx 160,176$, $220 \mathrm{~nJ}$, where the diameter and period of the microholes are $\mathrm{d} \approx 2,3,4 \mu \mathrm{m}$ and $\mathrm{p} \approx 6 \mu \mathrm{m}$, respectively. Traces of the melting of the surface and recrystallization of metal nanocrystal grains after the irradiation by a single ultrashort laser pulse with the energy $E \approx 176 \mathrm{~nJ}$ are seen in Figure 3b, 3c. It notes that this is not accompanied by visible separation of the film from the substrate. Figure $3 \mathrm{c}$ shows magnified images of the microhole with diameter $\mathrm{d} \approx 3 \mu \mathrm{m}$ with nanojet. The produced silver nanoparticle contacts weakly connecting the nanojet. This nanojet ejects the nanoparticle to a certain distance from the microhole until finally total separation. This effect is successfully applied to create regular arrays of nanoparticles by their deposition directly on an additional substrate [5].

A metallic nanojet is one of the most important nanostructures because it can locally enhance an electromagnetic field owing to the so called lightning rod effect. In fact, this experiment cannot be explained by the existing models based either on the molecular dynamics method or on the solution of a continuous problem of the propagation of elastic waves and plastic deformations in a heated film. The exfoliation in the formation of microholes are seen on the edge of holes in the form of "frozen" nanojets (Figure 2b, 3b and 3c) or even a nanoparticle of the material (see Figure $3 \mathrm{~b}$ and $3 \mathrm{c}$ ), which is a frozen droplet of the melted film. The maximum evaporation rate is achieved (neglected nonlinear thermophysical effects) just at the maximum of the radiation intensity (at the centre of laser Gaussian pulse). The threshold pressure significantly depends on $\mathrm{h}$, which plays the decisive role of cohesion, i.e., rupture over the melt film rather than over the film-substrate interface. The threshold pressure for thin films increases nonlinearly with the thickness. The values $\varepsilon \leq \Delta \mathrm{H}_{\text {vap }}$ should be achieved over the entire thickness of a film (size effect), but threshold pressures necessary for the rupture of thicker films are obviously much higher. We assume that the formation and development of the nanojet and the formation of nanoparticles are due to the thermo-capillary instability of the melted film. Because of a low thermal conductivity of a dielectric substrate, the melting of the film results the temperature gradient $\mathrm{T}$ to be orthogonal to the irradiated film surface.

By using laser pulse energy of $E \approx 220 \mathrm{~nJ}$, the microholes with diameter $\mathrm{d} \approx 4 \mu \mathrm{m}$ are fabricated as shown in the Figure $3 \mathrm{~d}$. The characteristic radius of holes (thermal spot) $R_{\text {hole, } 1 / \mathrm{e}}$ increase monotonically with $\mathrm{h}$. It means that due to slowly ablated rate (particularly, near the spallation threshold $\Phi_{\text {hole }}$ and for thick films), films can be heated up to $\Delta \mathrm{H}_{\text {vap }}$ and completely evaporated, as seen in the inner edge of holes (Figure 2a, 2c, 2d and 3).

Thus, estimates of the total absorbed volume energy density and characteristic topologies of microholes are the characters of the formation of microholes. The microholes were produced due to subsurface boiling, rather than to thermocapillary effects in the melted silver film and to elastoplastic effects of its deformation. 

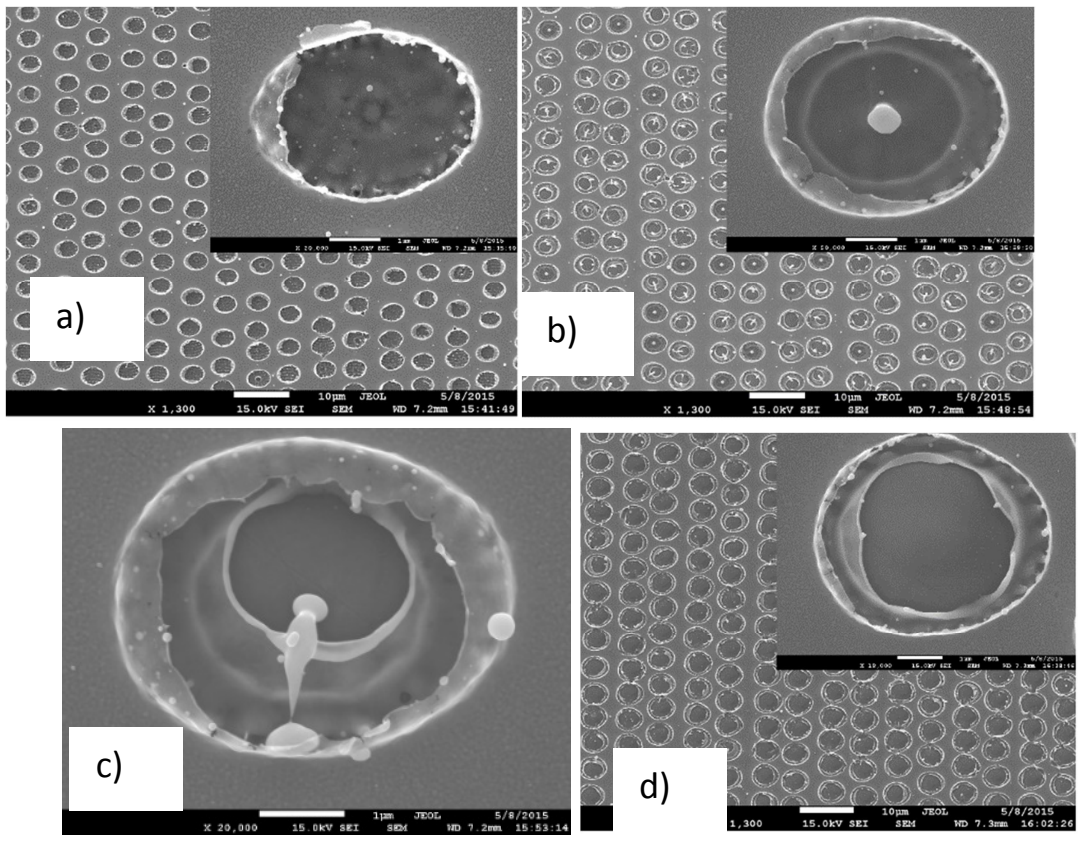

Figure 3. Scanning electron microscopy (SEM) image of the diffraction grating with diameter $\mathrm{d} \approx$ (a) 2, (b, c) 3, (d) $4 \mu \mathrm{m}$ and period $\mathrm{p} \approx 6 \mu \mathrm{m}$ of microhole arrays in the $150 \mathrm{~nm}$ thick silver film formed by strongly focused ultrashort laser pulses with the energy $E \approx$ (a) 160, (b, c) 176, (d) $220 \mathrm{~nJ}$ in the single pulse ablation regime. (c) Magnified images of the microhole with diameter $\mathrm{d} \approx 3 \mu \mathrm{m}$ with the nanojet. Scale bar: $10 \mu \mathrm{m}$.

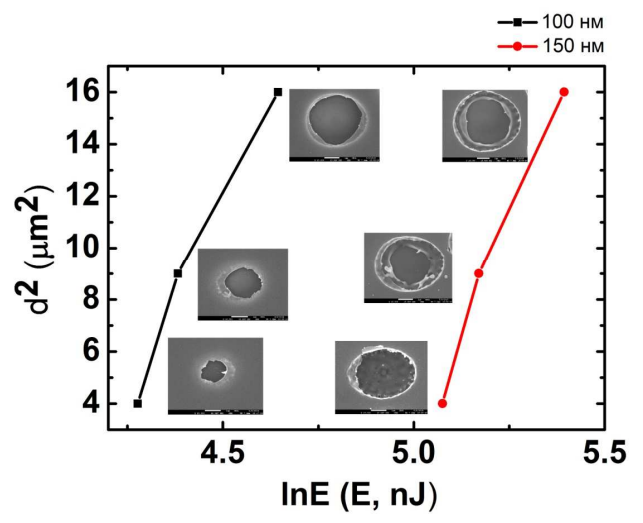

Figure 4. Diameters of the microholes in thin silver film with different thicknesses versus the natural logarithm of the laser energy (black squares $100 \mathrm{~nm}$, red circulars $-150 \mathrm{~nm})$. The inset shows the scanning electron microscopy image of the microholes with $d_{1} \approx 2 \mu \mathrm{m}, d_{2} \approx 3 \mu \mathrm{m}$ and $d_{3} \approx 4 \mu \mathrm{m}$ irradiated by a single ultrashort laser pulse.

Figure 4 shows dependence of the diameter squared of microholes on the natural logarithm of the laser energy with different thickness of silver film $100 \mathrm{~nm}$ (left curve), $150 \mathrm{~nm}$ (right curve). It shows that in the same thickness of the silver film, microhole of array has the larger diameter to the higher energy of laser pulses, while for the same diameter of microhole, the thicker silver film the higher energy of laser pulses is applied.

\section{CONCLUDING REMARKS}

In conclusion, we have demonstrated fabrication of periodic metallic microhole arrays in the thin Ag film with different thickness 100, $150 \mathrm{~nm}$. Microhole arrays with diameter 2, 3, 4 
$\mu \mathrm{m}$ and period $6 \mu \mathrm{m}$ can be easily fabricated by using single femtosecond laser pulses with variable pulse energies. Mechanism of the formation of microholes on silver film has been found that the characteristic radius of the formation region of nanostructures depends on the thickness of a film and on the duration of laser pulse. Using the measured absorbance of the silver film, the microhole has been explained to due to subsurface explosive boiling, rather than of simple surface evaporation of the film. These microhole arrays can be used as, e.g., a sensor in engineering, biology or medicine. They have extraordinary optical transmission and a lot of optical interesting properties.

\section{REFERENCES}

1. Chichkov B. N., Momma C., Nolte S., Alvensleben F., and Tünnermann A. Femtosecond, picosecond and nanosecond laser ablation of solids, Appl. Phys., A Mater. Sci. Process. 63 (2) (1996) 109-115.

2. Nolte S., Momma C., Jacobs H., Tünnermann A., Chichkov B. N., Wellegehausen B., and Welling H. - Ablation of metals by ultrashort laser pulses, J. Opt. Soc. Am. B 14 (10) (1997) 2716-2722.

3. Markus Weiler, Stefan B. Quint, Simon Klenk and Claudia Pacholski. - Bottom-up fabrication of nanohole arrays loaded with gold nanoparticles: extraordinary plasmonic sensors, Chem. Commun. 50 (2014) 15419.

4. Shailabh Kumar, SudhirCherukulappurath, Timothy W. Johnson, and Sang-Hyun Oh. Millimeter-Sized Suspended PlasmonicNanoholeArrays for Surface-Tension-Driven Flow-Through SERS, Chem. Mater. 26 (22) (2014) 6523-6530.

5. Emel'yanov V. I., Zayarniy D. A., Ionin A. A., Kiseleva I. V., Kudryashov S. I., Makarov S. V., Nguyen T. H. T., and Rudenko A. A. - Nanoscale Hydrodynamic Instability in a Molten Thin Gold Film InducedbyFemtosecond Laser Ablation, JETP Letters 99 (9) (2014) 518-522.

6. Danilov P. A., Zayarnyi D. A., Ionin A. A., Kudryashov S. I., and Makarov S. V., Rudenko A. A., Yurovskikh V. I., Kulchin Yu. N., Vitrik O. B., Kuchmizhak A. A. Mechanisms of formation of sub- and micrometre-scale holes in thin metal films by single nano- and femtosecond laser pulses, Quantum Electronics 44 (6) (2014) 540.

7. Debby Correia-Ledo, Kirsty F. Gibson, Anuj Dhawan, Maxime Couture, Tuan Vo-Dinh, Duncan Graham, and Jean-Francois Masson - Assessing the Location of Surface Plasmons Over Nanotriangle andNanohole Arrays of Different Size and Periodicity, J. Phys. Chem. C. 116 (2012) 6884-6892.

8. Hyungsoon Im, Si Hoon Lee, Nathan J. Wittenberg, Timothy W. Johnson, Nathan C. Lindquist, Prashant Nagpal, David J. Norris, Sang-Hyun Oh. - High-throughput fabrication of plasmonic nanohole array sensors for label-free kinetic biosensing, 15th International Conference on Miniaturized Systems for Chemistry and Life SciencesSeattle, Washington, USA, October 2-6 2011, pp. 416-418.

9. Kulchin Yu. N., Vitrik O. B., Kuchmizhak A. A., Savchuk A. G., Nepomnyashchii A. A., Danilov P. A., Zayarnyi D. A., Ionin A. A., Kudryashov S. I., Makarov S. V., Rudenko A. A., Yurovskikh V. I., Samokhin A. A. - Formation of nanobumps and nanoholes in thin metal films by strongly focused nanosecond laser pulses, Journal of Experimental and Theoretical Physics 119 (1) (2014) 15-23. 
10. Ramirez-San-Juan J.C., Padilla-Martinez J.P., Zaca-Moran P., and Ramos-Garcia R. Micro-hole drilling in thin films with $\mathrm{cw}$ low power lasers, OPTICAL MATERIALS EXPRESS 1 (4) (2011) 598.

11. Kulchin Y. N., Vitrik O. B., Kuchmizhak A. A., Nepomnyashchii A. V., Savchuk A. G., Ionin A. A., Kudryashov S. I., and Makarov S. V. - Through nanohole formation in thin metallic film by single nanosecond laser pulses using optical dielectric apertureless probe, Optics Letters 38 (9) (2013) 1452 - 1454.

12. Kautek W., Krüger J.,Lenzner M., Sartania S., Spielmann C., and Krausz F. - Laser ablation of dielectrics with pulse durations between 20 fs and 3 ps, Appl. Phys. Lett. 69 (21) (1996) 3146-3148.

13. Nityanand Sharma, Hamid Keshmiri,Xiaodong Zhou,Ten It Wong,Christian Petri,Ulrich Jonas,Bo Liedberg,and Jakub Dostalek. - Tunable PlasmonicNanohole Arrays Actuated by a Thermoresponsive Hydrogel Cushion, J. Phys.Chem.C. 120 (2016) 561-568.

14. Shibsekhar Roy and Joseph O’Mahony. - Nanohole Biosensor-Origin and Application as Multiplex Biosensing Platform, Austin J. Biosens\&Bioelectron. 1 (3) (2015) 1-3.

15. Blanca Caballero, Antonio García-Martín, and Juan Carlos Cuevas. - Hybrid Magnetoplasmonic Crystals Boost the Performance of Nanohole Arrays as Plasmonic Sensors, ACS Photonics 3 (2) (2016) 203-208.

16. Ulrich R. - Modes of Propagation on an Open Periodic Waveguide for the Far Infrared, Optical and Acoustical Micro-electronics; Polytechnic Press: New York, 1974, pp. 359376.

17. Glass N. E., Maradudin A. A., Celli V. - Diffraction of light by a bigrating: Surface polariton resonances and electric field enhancements, Phys. ReV. B: Condens. Matter Mater. Phys. 27 (1983) 5150.

18. Ebbesen T. W., Lezec H. J., Ghaemi H. F., Thio T., and Wolff P. A. - Extraordinary optical transmission through sub-wavelength hole arrays, Nature 391 (1998) 667-669.

\title{
TÓM TĂT
}

\section{CHẾ TẠO MẢNG VI LỖ TRÊN MÀNG MỎNG Ag BỞI XUNG LASER FEMTO GIÂY}

\author{
Nguyễn Thị Huyền Trang ${ }^{1,2,3}$ \\ ${ }^{I}$ Truờng Đại học Hà Tĩnh, 447, Đưòng 26/3, Phuờng Đại Nài, TP. Hà Tĩnh, Việt Nam \\ ${ }^{2}$ Viện vật lý Lebedev, Viện Hàn lâm KH Nga, 53 Đại lộ Lênin, Matxcơva, 119991 Nga \\ ${ }^{3}$ Trường Vật lý Kỹ thuật Matxcơva, 9 Đường Đại học, Dolgoprudnyi, Vùng Matxcơva, \\ $141700 \mathrm{Nga}$ \\ *Email: trang.nguyenthihuyen@htu.edu.vn
}

Mảng vi lỗ có đường kính khác nhau 2, 3, $4 \mu \mathrm{m}$ và chu kì $6 \mu \mathrm{m}$ được chế tạo trên màng mỏng bạc $\mathrm{Ag}$ với độ dày $100 \mathrm{~nm}$ và $150 \mathrm{~nm}$ sử dụng xung laser femto giây có năng lượng xung khác nhau được hội tụ bằng những thiết bị quang học hội tụ mạnh khác nhau. Những vi lỗ được chế tạo này có kích thước và hình dáng rất đều trên khắp vùng lớn của mẫu. Khi chiếu xạ bằng 
xung laser siêu ngắn lên màng mỏng kim loại không những làm tan chảy màng mà nó còn bị bong tróc dưới hình dạng tia nano (nanojets). Kính hiển vi lực nguyên tử và kính hiển vi điện tử được dùng để quan sát hình dạng và cấu trúc nano. Cũng như thông số ngưỡng của bức xạ laser cho sự hình thành của chúng được xác định bởi độ dày của màng và bởi khoảng thời gian của xung laser do sự dẫn nhiệt bên trong màng. Cơ chế hình thành vi lỗ trên màng mỏng bạc $\mathrm{Ag}$ bởi xung laser femto giây đã được thảo luận.

Tù khóa: laser femto giây, vi lỗ, màng mỏng, SEIRA. 